\title{
A FORMAÇÃO DO PROFESSOR DE GEOGRAFIA: A CONSTRUÇÃO DA IDENTIDADE PROFISSIONAL
}

\author{
Raimunda Abou Gebran \\ Universidade do Oeste Paulista - UNOESTE, Mestrado em Educação, Presidente Prudente, SP. E-mail: \\ ragebran@hotmail.com
}

\begin{abstract}
RESUMO
A presente pesquisa teve por objetivo analisar a formação do professor em cursos de Licenciatura em Geografia de duas instituições de ensino superior (pública e privada) de Presidente Prudente, buscando compreender como se revela a construção da identidade profissional. A pesquisa se justificou pela necessidade de reflexão sobre a formação do docente de Geografia proposta por esses cursos, apontando os avanços e as limitações desse processo, com vistas a sua redimensão. A pesquisa se configurou em uma perspectiva qualitativa, apoiada em revisão da literatura e análise documental (projeto pedagógico dos cursos). O trabalho permitiu desvelar o conjunto de elementos que, de forma direta ou indireta, direcionam e definem o processo de formação do licenciado e compreender como esse processo contribui para uma futura atuação docente na educação básica cujas habilidades e competências revelem a identidade e a profissionalização docente.
\end{abstract}

PALAVRAS CHAVE: Formação docente, Licenciatura em Geografia, identidade profissional.

\section{THE FORMATION OF THE BRAZILIAN STATE: THE PUBLIC POLICIES FOR THE INSERTION OF NEW TECHNOLOGIES IN EDUCATION}

\begin{abstract}
The present research had the objective of analyzing the teacher training in undergraduate courses in Geography of two higher education institutions (public and private) of Presidente Prudente, seeking to understand how the construction of the professional identity is revealed. The research was justified by the need for reflection on the training of the Geography teacher proposed by these courses, pointing out the advances and the limitations of this process, with a view to its redimensioning. The research was configured in a qualitative perspective, supported by literature review and documentary analysis (pedagogical project of the courses). The work allowed to unveil the set of elements that, directly or indirectly, direct and define the process of formation of the licensee and understand how this process contributes to a future teaching performance in basic education whose skills and competences reveal the identity and professionalism of the teacher.
\end{abstract}

KEYWORDS: Teacher training, Degree in Geography, professional identity. 


\section{INTRODUÇÃO}

A educação no Brasil passa por profundas mudanças, talvez não tantas quanto a sociedade atual exigiria, mas sem dúvida significativas. Nesse contexto, a Geografia, como componente curricular da escola básica, também se modifica, seja por força das políticas públicas, seja por exigências da própria ciência, uma vez que consideramos que a leitura do mundo é fundamental para que todos nós, que vivemos em sociedade, possamos exercitar nossa cidadania.

A compreensão da complexidade do fazer educativo traz à tona a figura do docente, seus compromissos, sua formação e sua percepção do exercício profissional. A formação para a docência passa a ser estudada em relação à prática pedagógica, autonomia e identidade profissional. O professor, como educador, ao trabalhar com o ensino de Geografia tem diante de si uma sociedade extremamente complexa, permeada de desigualdades e contradições o que torna relevante o seu trabalho considerando os problemas sociais que se desencadeiam nesse processo.

Nesta pesquisa, colocamos a construção da identidade profissional como objeto de estudo. A identidade profissional dos professores consiste no conjunto de formas de ser e atuar configuradas ao longo de sua vida docente. É o processo de construção e reconhecimento de uma definição de si, satisfatória para o próprio sujeito e válida para as instituições onde exerce a profissão.

Buscamos nessa pesquisa abordar os aspectos fundamentais que envolvem a formação do professor, mais especificamente a identidade do professor de Geografia, que se constituem em elementos de sua profissionalização. Assim, o objetivo central foi analisar a formação do professor em cursos de Licenciatura em Geografia de duas instituições de ensino superior (pública e privada) de Presidente Prudente, buscando compreender como se revela a construção da identidade profissional.

A pesquisa se configurou como uma investigação qualitativa, assumindo caráter analítico interpretativo. Os procedimentos da pesquisa estiveram centrados na revisão da literatura pertinente ao tema e na análise documental (documentos oficiais, legislações e projetos pedagógicos dos cursos).

\section{REFLEXÕES SOBRE A FORMAÇÃO DO PROFESSOR DE GEOGRAFIA}

A abordagem da formação do profissional docente de Geografia é um tema que deve levar em conta as diferentes transformações pelas quais o mundo tem passado, que provocam alterações no que diz respeito ao mundo do trabalho e à formação do professor e que afetam a formação e a identidade dos profissionais.

Para a atuação profissional do professor de Geografia exigida na atualidade não se podem mais adiar importantes modificações nos currículos e nas metodologias de formação inicial. Exigese uma formação que dê conta da construção e reconstrução dos conhecimentos geográficos fundamentais e de seu significado social. Não basta o professor ter domínio da matéria é necessário tomar posições sobre as finalidades sociais da Geografia numa determinada proposta de trabalho. É preciso que o professor saiba pensar criticamente a realidade social.

Portanto, essa reflexão deverá ser ancorada num suporte teórico crítico que vincule o objeto da Geografia, seus conceitos referenciais, conteúdos de ensino e abordagens metodológicas aos determinantes sociais, econômicos, políticos e culturais do atual contexto histórico. Para isso, será necessário ter como perspectiva tanto os períodos precedentes, quanto os possíveis movimentos de transformações futuros, numa análise que considere, permanentemente, o processo histórico (BRASIL, 2008 p. 50).

Outro papel importante que tem sido considerado importante na formação do professor é o da construção da identidade profissional e seu papel na formação. Sobre esse assunto, Callai (2006, p. 91) observa que: 
o conteúdo da Geografia é o material necessário para que o aluno construa o seu conhecimento, aprenda a pensar. Aprender a pensar significa elaborar, a partir do senso comum, do conhecimento produzido pela humanidade e do confronto com outros saberes (do professor, de outros interlocutores), o seu conhecimento. Este conhecimento, partindo dos conteúdos da Geografia, significa uma consciência espacial das coisas, dos fenômenos, das relações sociais que travam no mundo.

A formação do professor deve ser um processo contínuo, e deve ocorrer por toda a sua a vida profissional. Essa dimensão é apontada como formação continuada esse processo pode ocorrer em cursos de pós-graduação e de aperfeiçoamento nas práticas não escolares e nas práticas escolares.

Significa dizer que no exercício de suas funções no dia-a-dia da escola, o docente pode aprender e ampliar os conhecimentos de forma que isso possa redefinir os parâmetros que norteiam sua prática. É necessário que os professores dominem conhecimentos teóricos metodológicos da Geografia escolar assim como o ensino em geral para atuarem com consciência e autonomia. O desafio fundamental para o profissional da educação é distinguir e compreender as teorias subentendidas na sua própria prática e, originar condições para que diante das teorias, modifique seus pontos de vista, atitudes, posturas e atuação no exercício educacional.

Além da abordagem crítica da Geografia, esta também pode ser enriquecida por outras abordagens, ou seja, pela percepção que o indivíduo tem, ou que ele faz de seu mundo. Nessa perspectiva busca-se a apreensão do entendimento do aluno enquanto subjetividade, ou seja, a compreensão do lugar, do espaço vivido.

O ensino de Geografia demanda uma postura também diferenciada, sobretudo, no que diz respeito ao estabelecimento de relações entre os diferentes atores sociais que compõem o coletivo escolar e o próprio conhecimento.

Por isso cabe ao professor entender as especificidades inerentes a Geografia, mas desconstruir o caráter de fragmentação que a envolve de forma a intervir no processo de ensinoaprendizagem valorizando o entendimento do espaço geográfico como uma extensão humana e física.

\section{ANÁLISE DOS DADOS}

\section{ANÁLISE DO PROJETO PEDAGÓGICO DOS DOIS CURSOS DE GRADUAÇÃO}

Os cursos de graduação em Geografia podem, pelas Diretrizes Curriculares para os cursos de Geografia, oferecem as modalidades de licenciatura na Formação de Professores para o Ensino Básico e/ou bacharelado acadêmico profissionalizante.

Buscou-se compreender, nesta análise, a conceituação de identidade profissional do docente, assumida e objetivada pelos cursos, aceitando-se como definição de identidade profissional o conjunto de formas de ser e de atuar configuradas ao longo da vida docente.

Nesse sentido procurou-se compreender, a partir da análise dos dois projetos:

\section{A IDENTIDADE PROFISSIONAL DO PROFESSOR EXPRESSA NOS PROJETOS}

A profissionalização da docência, como processo de construção de identidades, é complexa, pois está relacionada à autoimagem, à autobiografia e às representações que os professores fazem de si próprios e dos outros no seu grupo profissional. Significa dizer que a construção da identidade envolve um lugar de lutas, de conflitos, em que são construídas as maneiras de ser e estar na profissão (Nóvoa, 1992). Assim, buscou-se compreender, nesta análise, a conceituação de identidade profissional do docente, assumida e objetivada pelos cursos, entendida como o conjunto de formas de ser e de atuar configuradas ao longo da vida docente. As análises 
revelaram que em ambos os cursos subentende-se a valorização do geógrafo e sua identidade profissional, mas não definem de modo claro e explícito a identidade da formação do professor de Geografia

\section{AS INTENCIONALIDADES DAS PROPOSTAS}

Ao analisar os objetivos gerais e específicos procurando destacar as intencionalidades e o perfil do profissional desejado bem como as competências e habilidades esperadas, verificou-se que estão bastante articuladas às Diretrizes Curriculares Nacionais. Contudo, são enfatizadas habilidades e competências que deverão ser adquiridas pelo geógrafo, mas não há referências à conceituação e importância da formação do professor. Entendemos que pensar nessa intencionalidade implica em pensar uma "nova profissionalidade docente", uma "nova cultura profissional", na qual se torna evidente que, como sintetiza Nóvoa (1992, p. 25), "a formação não se constrói por acumulação (de cursos, de conhecimentos ou técnicas), mas sim através de um trabalho de reflexividade crítica sobre as práticas e de (re)construção permanente de uma identidade pessoal".

\section{SABERES NECESSÁRIOS À PRÁTICA DOCENTE}

Um aspecto importante das pesquisas sobre o saber docente é a consciência do caráter social desse saber e da própria profissão do professor (TARDIF, 2006; GAUTHIER et al., 1998; NóVOA,1992). Nesse sentido, não basta ao professor possuir domínio da matéria (conteúdos), mas é fundamental que ele possua a capacidade de pensar criticamente, desvendar os fenômenos que permeiam a realidade social e que se imponha como sujeito transformador desta realidade. Assim, é determinante que na sua formação inicial lhe seja propiciada a oportunidade assumir um ponto de vista crítico sobre a organização do espaço geográfico, proporcionando o domínio do conteúdo a ser ensinado, como também a capacidade de refletir o próprio exercício docente. Como apontam Pontuschka, Paganelli \& Cacete,

À medida que os conteúdos deixam de ser fins em si mesmos e passam a ser meios para a interação com a realidade, fornecem ao aluno os instrumentos para que possa construir uma visão articulada, organizada e crítica do mundo. (2007.p.9)

\section{ESTRUTURA CURRICULAR}

A análise deste elemento do Projeto Pedagógico é reveladora do curso como organização e dos modos como se organiza, como se pensa e se (re) constrói no dia-a-dia, numa perspectiva de desenvolvimento curricular estratégico no qual, todos os atores são, tenham consciência disso ou não, construtores do currículo. A estrutura curricular de um curso aponta a intencionalidade de um trabalho que se completará com a prática, na constituição da práxis.

O currículo formal elaborado com a intencionalidade defendida nos documentos estudados e a pertinência dos elementos indicadores do trabalho a realizar, apesar de buscar o equilíbrio entre teoria e prática, deixa ainda, transparecer uma organização academicista com ênfase nas disciplinas. As ementas, cujo objetivo é indicar a função da disciplina no curso, em grande parte, apresentam a forma tradicional de elencar o conteúdo a ser desenvolvido.

\section{METODOLOGIA DO ENSINO}

Zeichner (apud Sá-Chaves, 1999, p. 35) afirma que "não é a prática que ensina, mas, a reflexão sobre ela". Diante disto é reduzida a possibilidade de analisar a metodologia do ensino sem observar a prática pedagógica dos professores e a reflexão que fazem sobre ela. Os projetos indicam apenas direções a serem assumidas na prática docente. s projetos indicam as direções a serem assumidas na prática docente. Contudo, pesquisas revelam que a ocorrência das 
dificuldades está relacionada à maneira como são conduzidas as didáticas e metodologias na realidade escolar. Kaercher afirma:

Insisto: os nossos maiores problemas não são de conteúdo, mas sim da falta de clareza, para nós mesmos, professores de Geografia, do papel da nossa ciência. Ou a geografia se torna útil para os "não geógrafos" (nossos alunos em especial), ou ela tende a desaparecer! Uma espécie de programa de variedades" que fala todos os lugares e povos diversos e distantes. Só que sem cores e sons. Chatice, portanto. (KAERCHER, 2009,p.230)

\section{PRÁTICAS AVALIATIVAS}

Nas Diretrizes Curriculares para os Cursos de Geografia, a referência à avaliação indica que "os cursos deverão criar seus próprios critérios de avaliação periódica, em consonância com os critérios definidos pela IES. à qual pertencem". A obediência a estes dois princípios de avaliação foram observados na proposta de avaliação na análise dos dois Projetos Pedagógicos.

Há a declaração de que os critérios e instrumentos de avaliação referentes ao ensino terão com finalidade a apreensão dos conhecimentos dos conhecimentos, competências e habilidades adquiridas pelos alunos no decorrer do curso e ressalta ainda que os instrumentos de avaliação (questionários, entrevistas) poderão ser aplicados com o objetivo de diagnóstico do trabalho pedagógico, do andamento e das dificuldades que o curso enfrenta e o objetivo de ajuste à ajuda. Contudo, não se expressa o caráter formativo das práticas avaliativas

\section{CONSIDERAÇÕES FINAIS}

O projeto pedagógico é elaborado como orientação para as atividades administrativas e pedagógicas que o curso necessita. Pode-se dizer que ele estabelece o "currículo formal" para ser vivenciado pelos docentes (currículo vivido). As duas instituições escolares estão a experimentar uma nova organização de um curso de Licenciatura em Geografia, estão a constituir um novocurrículo formal que orientará o currículo vivido por professores e alunos. Assim, o primeiro cuidado na elaboração do projeto pedagógico é sempre o de envolver os responsáveis pelo curso, especialmente os docentes. O conhecimento do que se pensa e se deseja com o curso deve ser trabalhado por todos, de modo a perceber a natureza do curso. Nos documentos estudados não se percebeu movimento neste sentido da participação e envolvimento para a percepção dos aspectos sociais econômicos e antropológicos que se vive hoje para ensinar.

\section{REFERÊNCIAS}

BRASIL, MEC. Diretrizes curriculares para cursos de Geografia - Parecer CES - 492/2001.

CALLAI, Helena C. A articulação teoria-prática na formação do professor de Geografia. In: SILVA, Aida Maria M. et. al. Educação formal e não formal, processos formativos e saberes pedagógicos: desafios para inclusão social. Encontro Nacional de Didática e Prática de Ensino. Recife: ENDIPE, 2006. p. 143- 161.

KAERCHER, N. A. O gato comeu a Geografia Crítica? Alguns obstáculos a superar no ensino aprendizagem de Geografia. In: PONTUSCHKA, N N. e OLIVEIRA, A. U. (orgs.). Geografia em Perspectiva: ensino e pesquisa. São Paulo: Contexto, 2009. p. 221-231.

NÓVOA, A. A profissão professor. Porto: Porto Editora, 1992. 
PONTUSCHKA, N.N., PAGANNELLI, T. I. CACETE, N. H. Para Ensinar e Aprender Geografia. São Paulo: Ed Cortez, 2007.

Projeto Pedagógico do Curso de Geografia DA FCT -Unesp -Presidente Prudente/SP, 2004.

Projeto Pedagógico do Curso de Licenciatura em Geografia -Unoeste -Presidente Prudente/SP, 2014.

SÁ-CHAVES, Idália. O currículo como meio ou instrumento. In: ROLDÃO, M. C. Currículo; gestão diferenciada e aprendizagens de qualidade. Algarve. Portugal, 1999, p. 23 a 40.

TARDIF, Maurice. Saberes docentes e formação profissional. Petrópolis, RJ: Vozes, 2010. 